\title{
Input or Output Oriented Tasks? A Question of Teaching Vocabulary in EFL Context
}

\author{
Behnaz Gholinezhad Khameneh \\ IAU Research and Science Center, Alborz Branch, Iran \\ E-mail: behnazqolinezhad@yahoo.com \\ Natasha Pourdana (Corresponding author) \\ ELT Department of Higher Education, Faculty of Literature and Foreign Languages, Islamic Azad University, Alborz Branch, Iran \\ E-mail: Natasha.qale@gmail.com
}

$\begin{array}{lll}\text { Received: 04-10-2015 } & \text { Accepted: 10-01-2016 } & \text { Advance Access Published: January 2016 } \\ \text { Published: 01-03-2016 } & \text { doi:10.7575/aiac.ijalel.v.5n.2p.238 } & \text { URL: http://dx.doi.org/10.7575/aiac.ijalel.v.5n.2p.238 }\end{array}$

\begin{abstract}
This research aimed at comparing the effectiveness of Output-oriented and Input-oriented tasks on improving EFL learners' vocabulary achievement. To reach their objective, the researchers ran a quasi-experimental pre-test posttest design with 64 Iranian EFL learners. After eliminating the initial differences among the participants, the Input-oriented group (IOG) received glossing tasks followed by selected reading passages, while the Output-oriented group (OOG) received gap-filling and composing/discussing tasks. Actively participating in 15 sessions of task-based vocabulary learning, both IOG and OOG performed on a vocabulary achievement test constructed and validated by the researchers (Cronbach $\alpha=.732$ ). Despite the considerable improvement of the participants' vocabulary knowledge, statistical findings failed to support the superiority of neither input nor output oriented tasks to make a meaningful difference in improving the Iranian EFL learners' vocabulary achievement. Some implications and suggestions provided for further research.
\end{abstract}

Keywords: EFL, Input-Oriented, Output-Oriented, Task, Vocabulary, Glossing, Gap-Filling

\section{Introduction}

Fortunately, upon the survival need for knowing vocabulary both language teachers and learners agree. As Khabiri and Pakzad (2012) argued, one of the necessary but challenging portion of language is its lexicon. Lexicon is the building block of a language without which people cannot communicate their intentions effectively. An approach claimed to be beneficial in coping with the problem of vocabulary learning is task-based language teaching wherein a variety of language tasks is employed as the main pedagogical tools to teach diverse lexical elements. Learning new words occurs through the process of completing tasks, as language learners becoming master over the new lexical items more powerfully when they are exposed to meaningful task-based activities in a natural way.

According to the proponents of task-based language teaching, the uptake of vocabulary, as one of the key elements in second language learning, is enhanced by employing proper pedagogical tasks. However, designing effective pedagogical tasks has always been a huge challenge for second language (L2) teachers (Saeidi, Zaferanieh, \& Shatery, 2012). The positive and comparative impacts of different task types on vocabulary learning is still open to question. The fact that this debate over the effectiveness of diverse task types in promoting vocabulary uptake remains unresolved indicates is urgent and productive to conduct further research in this regard.

There is a controversy among language teaching experts on two types of input-oriented and output-oriented tasks to teach vocabulary in formal language classrooms. The supporters of input-oriented tasks constantly argue that majority of the classroom practice should be exclusive to output-oriented tasks and the fluency in production should proceeds the input-based activities that encourage receptive comprehension. On the other hand, the promoters of output-oriented tasks claim that learners should initially employ authentic and fluent but unchallenging language material as in most natural settings of language use, the language is not well-formed in order to be meaningful.

Exploring the unexplored aspects of the task-based approach on vocabulary learning is a worth research. Becoming aware of how tasks can affect vocabulary learning may help EFL teachers decide on the appropriate and practical type of teaching activities in order to facilitate the EFL learners' vocabulary development. Inspired by this need, the current study had a hypothetical assumption that the input-orient and out-put oriented tasks would contribute differently into the EFL learners' vocabulary improvement. The major concern of the researchers was formulated into a research question as if Is there any significant difference between the vocabulary retrieval of the Iranian EFL learners who receive InputOriented tasks and those who receive Output-Oriented task. 
By definition, "input" refers to the available materials to be used by language learners for language learning while "intake" is the portion of the input comprehended and retained by the target learners (Corder, 1967). Corder believed that the intake rather than the input would help better the language learners to raise their language proficiency. While the importance and the role of the language input has been constantly supported, there are some educators who attributed a small or even no role to language input as it was highlighted by Ellis (2008). He addressed the theories of second language learning as being too much attached and underscoring the role of language input while they all have implicitly acknowledged the output as indispensable and survival. This negligence may be due to the fact that various theorists have different conceptualizations of how language input is processed by different language learners (Doughty \& Long, 2003).

Ellis (2008) elaborated on the role of language input through restating the behaviorist, mentalist, and interactionist viewpoints of successful language learning. The behaviorists underscored the environmental control in the process of language acquisition, since language learners are exposed to the language input in terms of received stimulus and the external and immediate feedback on their quality of response. Similarly, the mentalists argued that the ample and comprehensible input is a requirement, despite the learners' brains being genetically apt to learn human languages; hence language input is a trigger that activates the internal learning mechanism (Ellis, 2008). The interactionists seemed to stand in the middle of these two positions to highlight the importance of both language input and internal learning mechanism. To them, language acquisition is the product of an interaction at the discourse level between the learners' mental abilities and the linguistic environment. Elaborated in Krashen's Comprehensible Input Hypothesis (1981), if only the language input is a little beyond the language learners' level of competence $(i+1)$ it can contribute into second language learning process, or in Corder's terms "may be considered as equal to intake" (1967).

In a study conducted with Canadian immersion learners, Swain (1985) proved that even though language learners received abundant comprehensible input in French, they hardly acquired the grammatical competence in French as the second language (FSL). The participants in this program had numerous syntactical errors in French to make the language teachers suspect the target language grammatical system fully acquired merely by being in a rich environment with the target language input (Lightbown \& Spada, 2005). Swain (1995) suggested that the "output" was the missing factor and called this survival kit the "Output Hypothesis". She believed that one possible way for language teachers to improve grammatical accuracy was demanding their students to produce enough language output. She further speculated that the French language learners attended the Canadian immersion setting were not "pushed" enough into the deeper analysis of the target language grammar because they could convey their meaning adequately without doing so.

It is generally believed that language learners should work harder to produce the target language than to comprehend it. It is partially true as when they are actively producing comprehensible output, they are restricted by an intensive demand to be as accurate as possible. This is in a sharp contrast with what was attributed to the comprehensible input in which learners were believed to have a considerable interest and openness when they are exposed to the target language (Ellis, 2008). It was proposed that comprehensible output could (a) provide language learners with opportunities for more contextualized and meaningful language use, (b) allow them to test out their initial assumptions and hypotheses drawn upon the target language structures and (c) force them to move from semantic to the syntactic processing of the target language.

A number of researchers experimentally probed the relative benefits of input and output oriented tasks in terms of their effects on foreign language learners' improvement of the target language components and skills. Vosoughi and Mehdipour (2013) investigated on the influences of two types of language production and recognition tasks on the 78 English as a foreign language (EFL) learners' incidental vocabulary learning. They reported that both types of tasks improved the incidental vocabulary learning to a considerable amount, however, the production tasks yielded better results in the vocabulary achievement test. On the same line, Ghabanchi, et al. (2012) conducted two experiments on the comparative effects of the involvement load and task types on vocabulary learning in the EFL context. With the 56 Iranian adult EFL learners, they recorded a deeper involvement in their subjects' performance on the output-oriented tasks that caused more improvement in their English vocabulary learning. Yaqubi et al. (2010) followed Laufer and Hulstijn's (2001) motivational-cognitive construct of task-induced involvement to address the depth of processing as an overriding factor in learning vocabulary in the EFL context. They re-examined the influences of vocabulary processing load in input and output-oriented tasks. The performance of three groups of 60 participants on one input and two outputoriented tasks with the involvement load index of 3,2, and 2, respectively. The researchers concluded that the groups' success on completing the tasks was more a matter of task type than the involvement load, since they performed equally well on output-oriented tasks with different involvement load indices of 2 and 3. Their lowest performance on inputoriented task once more highlighted the task type as a more effective factor than processing load.

To focus on the age of the language learners as a critical factor in the EFL context, Shintani (2011) investigated the comparative effects of input and output oriented tasks on the vocabulary acquisition of young EFL learners. Thirty-six Japanese children aged 6 to 8 years old were divided into three input-based, production-based and control groups to receive six weeks task-based instruction and took four types of vocabulary tests as pre-, post- and delayed tests. The findings provided more evidence to support the effectiveness of both input-based and production-based instructions, with an exceeding amount of interaction in production-based tasks. To further support the role of output-oriented tasks on listening comprehension of the young EFL learners, Ellis and Xien (1999) set an experiment. They investigated the 
differential effects of two pre-modified and interactionally modified input-oriented tasks, as well as modified outputoriented tasks on the comprehension of directions in a listen-and-do test as well as the acquisition of new words embedded in the directions. The modified output-oriented group performed noticeably better on listening comprehension and vocabulary achievement tests than both other input groups in this study.

Once more, the researchers emphasized the role of qualitatively superior dialogic interactions in terms of actual language production that occurred among the modified output group members. Inspired by the ample and disputable experiments done on the effectiveness of input and output oriented tasks, the current study was conducted with three types of the input-oriented glossing and output-oriented gap-filling and composing/discussing tasks to investigate the possible differences they would make on the EFL learners' vocabulary learning.

\section{Method}

\subsection{Participants}

A total of 64 Iranian EFL learners participated in this study. The sample included only male EFL learners ranging from 13 to 21 years of age learning English as a Foreign Language (EFL) at a private language institute in Tehran in 2014. To eliminate the selection bias, four intact classes of language students were randomly assigned into two experimental groups (From now on, Input-Oriented group (IOG) and Output-Oriented group (OOG)). The size of the participants in IOG and OOG was 29 and 35, respectively. The participants' initial within-group differences were eliminated with running a Preliminary English Test (PET) by excluding 3 outliers whose scores fell off beyond 2SD from the mean score.

\subsection{Instruments}

In this study, two measuring instruments were used. Firstly, the Preliminary English Test (PET) as the pretest in order to ensure the homogeneity of participants in their level of general English proficiency. Secondly, a Vocabulary Achievement Test (VAT) constructed and validated by the researchers from the content of the course book Top Notch $3 B$ (Saslow, 2010) as the posttest to assess the vocabulary achievement of the participants. The VAT consisted 65 multiple choice items, including 10 listening comprehension items, 10 grammar items, 20 vocabulary items presented and practiced following the course syllabus, 10 reading comprehension items and a 5-point scaled writing section that required the participants to write short paragraphs on the intended topics. The internal validity of the VAT was statistically measured with Cronbach $\alpha=.732$.

\subsection{Materials}

2.3.1 Target words. Before running the experiment, a list of 140 words expected to be unfamiliar to the participants was randomly selected out of Top Notch $3 B$ from which 75 word items were picked up by a group of language students similar to the target sample. The target words were a collection of nouns, verbs and adjectives in their parts of speech.

2.3.2 Reading texts. A series of reading passages with similar level of difficulty and length was adopted from Top Notch $3 B$ and its companion $C D$. The pilot group of students rated the themes and topics of the texts as interesting and suitable for the main participants since they were supposed to have some degree of familiarity to the selected words. Ten multiple-choice and true-false vocabulary check items followed every reading text.

2.3.3 Glossing Task. As an Input-Oriented task, the participants in IOG were provided with short passages followed by 10 reading comprehension items where the exerted words from the text had to be matched with their L1 equivalents and their L2 definitions on the slides or boards.

2.3.4 Gap-filling Task. As an Output-Oriented task, the participants in OOG were provided with short passages and fillin-the-blank items. A number of exerted words from the text, along with the words selected by the pilot group before the treatment started, was incorporated into fill-in-the-blank items printed in random order on a separate sheet. The participants were required to fill in the gaps with appropriate words.

2.3.5 Composing/Discussing Task. As an Output-Oriented task, the participants in OOG were required to write 150-200 words paragraphs on the selected topics.

\section{Results and discussion}

The scores of IOG and OOG on the pre-test PET were descriptively analyzed and presented in Table 1.

Table 1. Descriptive Statistics for IOG and OOG on PET

\begin{tabular}{|c|c|c|c|c|c|c|c|c|}
\hline \multirow[b]{2}{*}{ Group } & \multirow[t]{2}{*}{$\mathrm{N}$} & \multirow[t]{2}{*}{ Min } & Max & \multicolumn{2}{|c|}{ Mean } & SD & \multicolumn{2}{|c|}{ Skewness } \\
\hline & & & & Statistic & Std.Error & & Statistic & $\begin{array}{l}\text { Std. } \\
\text { Error }\end{array}$ \\
\hline IOG & 29 & 73.00 & 87.00 & 78.18 & 1.64 & 3.28 & -.662 & .117 \\
\hline OOG & 35 & 71.00 & 88.00 & 75.59 & 0.61 & 4.45 & -.795 & .141 \\
\hline
\end{tabular}

As Table 1 represents, IOG and OOG scores on PET have similar ranges of dispersion and mean scores, however, the standard deviation for OOG $\left(\mathrm{SD}_{\mathrm{OOG}}=4.45\right)$ reports a wider scope of scores than in $\mathrm{IOG}\left(\mathrm{SD}_{\mathrm{IOG}}=3.28\right)$. Both sets of scores were negatively skewed. 
To test the normality of the scores distribution, the Kolmogorov-Smirnov test was conducted. The insignificant amount of $\mathrm{Z}$ for both tests, proved the normal distribution of scores in PET ( $\mathrm{z}=0.873, \mathrm{p}<0.05)$. The scores of IOG and OOG on Vocabulary Achievement Test (VAT) as the post-test were descriptively analyzed and presented in Table 2.

Table 2. Descriptive Statistics for IOG and OOG on VAT

\begin{tabular}{ccccccccc}
\hline \multirow{2}{*}{ Group } & $\mathrm{N}$ & Min & Max & \multicolumn{2}{c}{ Mean } & \multicolumn{2}{c}{ SD } & \multicolumn{2}{c}{ Skewness } \\
\cline { 2 - 9 } & & & \multicolumn{3}{c}{ Statistic Std.Error } & & Statistic & Error \\
\hline IOG & 29 & 38.00 & 48.00 & 42.18 & 1.64 & 2.58 & -.462 & .317 \\
OOG & 35 & 36.00 & 48.00 & 42.59 & 0.61 & 3.08 & -.795 & .241 \\
\hline
\end{tabular}

Based on the data presented in Table 2, the researchers concluded that the performance of IOG and OOG on VAT was less successful than their performance on PET pre-tests, with similar post-test results for IOG and OOG. The assumption of Homogeneity of Variances was not rejected in Levene's Test; therefore, to testify the hypothetical assumption on relative impact of Input-oriented and Output-oriented tasks on EFL learners' vocabulary achievement, a One Way ANOVA was run between the PET scores and VAT scores to investigate the IOG and OOG's vocabulary improvement.

Table 3. One-Way ANOVA for PET and VAT

\begin{tabular}{|c|c|c|c|c|c|c|c|}
\hline & Variables & & Sum Squares & $\mathrm{df}$ & $\begin{array}{c}\text { Mean } \\
\text { Square }\end{array}$ & $\mathrm{F}$ & Sig. \\
\hline \multirow{5}{*}{ PET * VAT } & \multirow{3}{*}{$\begin{array}{l}\text { Between } \\
\text { Groups }\end{array}$} & (Combined) & 394.467 & 1 & 197.233 & 19.245 & .000 \\
\hline & & Linearity & 355.267 & 1 & 355.267 & 34.665 & .000 \\
\hline & & Deviation Linearity & 39.200 & 1 & 39.200 & 3.825 & .054 \\
\hline & \multicolumn{2}{|c|}{ Within Groups } & 891.633 & 64 & 10.249 & & \\
\hline & \multicolumn{2}{|c|}{ Total } & 1286.100 & 64 & & & \\
\hline
\end{tabular}

As displayed in Table 3, the index of $F=19.245$ is significant at the p-value $=.000$ for the IOG and OOG groups' performance on PET and VAT. Therefore, it can be assumed that both input and output-oriented tasks improved the participants' vocabulary achievement during the treatment sessions. To measure the size of this impact, Eta Squared was calculated for scores on PET and VAT. The measures of association is presented in Table 4.

Table 4. Effect Size: VAT Post-test Scores

\begin{tabular}{ccccc}
\hline Variables & $\mathrm{R}$ & R Squared & Eta & Eta Squared \\
\hline VAT $*$ Groups & .526 & .276 & .554 & .307 \\
\hline
\end{tabular}

Table 4 displays the measure of $\mathrm{Eta}^{2}{ }_{\text {Post-test }}=.307$. To interpret this measure, a reference was made to Pierce et al. (2004). Accordingly, $\mathrm{Eta}^{2}=.02$ can be interpreted as a small effect size and $\mathrm{Eta}^{2}=.26$ as a large effect size. Therefore, it was concluded that the effect size of the conducting Input-oriented and Output-oriented tasks on the participants' vocabulary improvement was large enough to claim their meaningful impact on Iranian EFL learners' vocabulary achievement. In order to investigate the relative differences of the participants' performance on the Glossary input-oriented task, Gapfilling and Composing/Discussing output-oriented tasks, a multiple comparison was made by running a Scheffe Post Hoc test.

Table 5. Multiple Comparison among Input and Output Oriented Tasks Types

\begin{tabular}{|c|c|c|c|c|c|c|c|}
\hline \multirow[t]{2}{*}{ Tasks } & \multirow[t]{2}{*}{ (I) Tasks } & \multirow[t]{2}{*}{ (J) Tasks } & \multirow{2}{*}{$\begin{array}{c}\text { Mean } \\
\text { Difference (I- } \\
\text { J) }\end{array}$} & \multirow[t]{2}{*}{ Std. Error } & \multirow[t]{2}{*}{ Sig. } & \multicolumn{2}{|c|}{$95 \%$ Confidence Interval } \\
\hline & & & & & & Lower Bo & er Bound \\
\hline \multirow{6}{*}{ Scheffe } & \multirow[b]{2}{*}{ Glossary } & Gap-filling & -1.03 & 1.68 & .520 & -5.22 & 3.16 \\
\hline & & $\begin{array}{c}\text { Comp/ } \\
\text { Discussing }\end{array}$ & -.53 & 1.68 & .951 & -4.72 & 3.66 \\
\hline & \multirow[b]{2}{*}{ Gap-filling } & Glossary & 1.03 & 1.68 & .829 & -3.16 & 5.22 \\
\hline & & $\begin{array}{c}\text { Comp/ } \\
\text { Discussing } \\
\end{array}$ & .05 & 1.68 & .957 & -3.69 & 4.69 \\
\hline & \multirow{2}{*}{$\begin{array}{c}\text { Comp/ } \\
\text { Discussing }\end{array}$} & Glossary & .53 & 1.68 & .951 & -3.66 & 4.72 \\
\hline & & Gap-filling & -.50 & 1.68 & .957 & -4.69 & 3.69 \\
\hline
\end{tabular}

*. The mean difference is significant at the 0.05 level.

As Table 5 suggests, the participants' performance on three types of Input-oriented (Glossary), and Output-oriented 
(Gap-filling and Composing/Discussing) tasks had different patterns.

- The mean difference for the participants' performance on Glossary (I) and Gap-filling (J) tasks did not show a radical and significant difference: $\mathrm{I}-\mathrm{J}=-.1 .03$ at $\mathrm{p}$-value $=.520$.

The mean difference for the participants' performance on Glossary (I) and Composing/Discussing ( $\mathrm{J}$ ) tasks did not show any significant difference: $\mathrm{I}-\mathrm{J}=-.53$ at $\mathrm{p}$-value $=.951$.

- The mean difference for the participants' performance on Gap-filling (I) and Composing/Discussing (J) tasks did not show any significant difference: $\mathrm{I}-\mathrm{J}=.50$ at $\mathrm{p}$-value $=.957$.

Referring to the data compared in Table 5, the researchers reported no meaningful differences among the participants' performance on three types of Input and Output oriented tasks in this study, despite their significant overall impacts on the improvement of the participants' performance on VAT. Therefore, it was concluded that both input and output oriented tasks made equally meaningful and statistically significant difference in the vocabulary achievement of the EFL learners, with no superiority of performance to one another.

\section{Conclusions}

The finding in this study was contradictory to a number of studies previously conducted on techniques and methods of improving English vocabulary achievement of EFL learners. In 2014, Song and Sordegna who investigated the effectiveness of production tasks versus recognition reading tasks on incidental vocabulary learning of EFL learners reported that both treatments have significant effects on incidental vocabulary learning but this effect was in favor of output-oriented tasks. Song and Sordegna justified this contradiction due to the different approaches they adopted to teach vocabulary implicitly, while the present study incorporated tasks to teach the targeted words exclusively extracted from the reading passages. Yaqubi et al. (2010) reported the superiority of the output-oriented tasks of similar involvement load to input-oriented tasks. This implies the fact that considering the issue of involvement load itself may add to the complexity of determining more effective approaches to teaching vocabulary than the input or output task orientedness.

Despite the discrepancy of the results in this study with some research in Asian EFL context, they hardly deny the fact that using a variety of input and output oriented tasks guarantees a better opportunity to enhance the vocabulary knowledge of the language learners. A number of factors might contribute into more concise and elaborate results, such as comparing the performance of the EFL learners at different level of language proficiency on input and output oriented tasks. The participants' gender can be a contributing factor too, as female language learners seem better and more apt at providing language output in Iranian EFL contexts. Finally, the possible differences that input and output oriented tasks could make in the improvement of language components and skills provide a more vivid picture and challenging research topics for the prospective EFL teachers and educators in Asian EFL contexts.

\section{References}

Corder, P. (1967). The significance of learner's errors. International Review of Applied Linguistics 20 (1), pp. 161-170.

Ellis, R. (2008). The study of second language acquisition (2nd Ed). Oxford: Oxford University Press.

Ellis, R. \& Xien, H. (1999). The Roles of Modified Input and Output in the Incidental Acquisition of Word Meanings. Studies in Second Language Acquisition 21(2). pp. 28-48.

Khabiri, Z. \& Pakzad, N. (2012). Effects of input and output-oriented tasks with different involvement loads on the receptive vocabulary knowledge of Iranian EFL learners. Iranian Journal of Research in English Language Teaching, 1 (1), pp. 65-88.

Krashen, S. D. (1981). The input hypothesis: Issues and implications. London: Longman.

Laufer, B. \& Hulstijn, J. (2001). Incidental Vocabulary Acquisition in a Second Language: The Construct of TaskInduced Involvement. Applied Linguistics, 22 (1), pp.1-26.

Lightbown, P. M. \& Spada, N. (2005). How languages are learned. Oxford: Oxford University Press.

Pierce, S., Yost, C., Britton, J. S., Loo, L.W.M., Flynn, E.M., Edgar, B.A., Eisenman, R.N. (2004). Self-esteem and inrole performance. Journal of Occupational and Organizational Psychology, 77(3), pp. 207-238.

Saeidi, M., Zaferanieh, E. \& Shatery, H. (2012). On the Effects of Focus on Form, Focus on Meaning, and Focus on Forms on Learners' Vocabulary Learning in ESP Context. English Language Teaching, 5(10), pp. 112-130.

Saslow, L. (2012). Topnotch Series. New York: Longman.

Song, M. J., \& Sordegna, B. R. (2014). The effects of output task type on noticing and learning of the English past counterfactual conditional. System, 36, pp. 295-312.

Swain, M. (1985).Communicative competence: some roles of comprehensible input and comprehensible output in its development. In S. Gass and C. Madden (Eds.), Input and Second Language Acquisition (pp. 235-253). New York: Newbury House.

Swain, M. (1995). Three Functions of Output in Second Language Learning. In G. Cook and B. Seidlhover (Eds.), principles and practice in the Study of Language. Studies in Honor of H.G. Widdowson (pp. 125-144). Oxford: Oxford University Press. 